\title{
RESEARCH
}

Open Access

\section{Predicting invasion potential of Senna didymobotrya (Fresen.) Irwin \& Barneby under the changing climate in Africa}

\author{
Elias Ch. Weldemariam ${ }^{1 *}$ (D) and Dejene Sintayehu W. ${ }^{2}$
}

\begin{abstract}
Background: Senna didymobotrya is a native African flowering shrub. It is suspected that climate change encourages the introduction and spread of invasive alien species. The possible invasion of S. didymobotrya across the continent is expected to increase in the future due to ongoing climate change. Nonetheless, there is still paucity of empirical evidence on the extent to which the changing climate contributes to the surge of the flowering shrub. This study, therefore, investigated the present and potential invasion of S. didymobotrya using the species distribution model under changing climate conditions. The two representative concentration pathways (RCP4.5 and RCP8.5) and eight bioclimatic variables and one topographic variable were used to simulate the current and future (2050s and 2070s) invasion of S. didymobotrya in Africa. The model performance was assessed using the area under the receiver operating characteristic curve (AUC) and true skill statistics (TSS).

Results: The results of the study showed that under the current climatic conditions, 18\% of Africa is suitable for the establishment and invasion of $\mathrm{S}$. didymobotrya. The most suitable hotspot for $\mathrm{S}$. didymobotrya invasion is eastern Africa, followed by southern Africa. The predicted model showed that by 2050, 3.3\% and 3.12\% of the continent would be highly suitable areas for the invasion of the species under RCP4.5 and RCP8.5, respectively. In the 2070s, under RCP4.5 and RCP8.5, the highly suitable area would be $3.13 \%$ and $2.7 \%$, respectively. In relation to the current suitability, the cumulative projected areas of the low and moderate suitability class under RCP4.5 and RCP8.5 will rise by the years 2050 and 2070. However, under both RCPs, the non-suitable area for S. didymobotrya invasion would gradually decrease.

Conclusions: From the findings, it can be concluded that the ecosystem's vulnerability to S. didymobotrya invasion under future climatic conditions will proliferate significantly. Hence, to prevent the projected harm to biodiversity and ecosystem services, governments need to focus their future biodiversity management and policy directions on the means and strategies of minimizing the invasion and the distribution rate of $\mathrm{S}$. didymobotrya across habitat types.
\end{abstract}

Keywords: Senna didymobotrya, Invasive species, Climate change, Africa, Ensemble approach

\footnotetext{
* Correspondence: eliachent@gmail.com

'Department of Geo-information Science, Haramaya University, Dire Dawa, Ethiopia

Full list of author information is available at the end of the article
}

\section{Springer Open}

(c) The Author(s). 2021 Open Access This article is licensed under a Creative Commons Attribution 4.0 International License, which permits use, sharing, adaptation, distribution and reproduction in any medium or format, as long as you give appropriate credit to the original author(s) and the source, provide a link to the Creative Commons licence, and indicate if changes were made. The images or other third party material in this article are included in the article's Creative Commons licence, unless indicated otherwise in a credit line to the material. If material is not included in the article's Creative Commons licence and your intended use is not permitted by statutory regulation or exceeds the permitted use, you will need to obtain permission directly from the copyright holder. To view a copy of this licence, visit http://creativecommons.org/licenses/by/4.0/. 


\section{Introduction}

Invasive alien species are posing a great threat to global biological diversity (Mainka and Howard 2010; Shiferaw et al. 2018) and agricultural productivity and economic growth (Simberloff et al. 2013). Human activities and climate changes have greatly contributed to changing the habitat range of invasive alien species at a faster rate than ever before (Walther et al. 2009). The rapidly growing human populations, increased human mobility, tourism, transport, and technological advancement (Wilson et al. 2009; Wittenberg and Cock 2001), and increasing international trade in agricultural and related products (Richardson and Rejmanek 2011) have greatly facilitated the movement of many invasive alien species from their native ranges into new areas. Once established in their habitat, invasive species can flourish and extend quickly into the new area and tends to harm the ecosystem function and structure (Masters and Norgrove 2010; Shiferaw et al. 2020), natural processes, and human activities (Luizza et al. 2016).

The currently increasing spread and risk of invasive alien plant species in Africa remain the most striking problem affecting the biological diversity losses and livelihood (Witt et al. 2018). This calls for an integrated approach. Over 164 invasive alien plant species were reported in Africa by Witt et al. (2018); of these, Senna didymobotrya (Fresen.) Irwin \& Barneby is among the most frequently reported invasive species. S. didymobotrya, also named as a bush encroacher, is known to suppress the regeneration and growth of native plant species by forming large dense impenetrable brushes and mono-cropping stands (Witt et al. 2018) and obstructing the movement of wild animals. It can easily establish itself in diverse habitat types, including grasslands, woodlands, forests, riparian zones, dumpsite, disturbed area, and coastal scrub (Tamiru 2017; Witt and Luke 2017). For instance, high invasion of S. didymobotrya was reported in forest reserves in Uganda (Winterbottom and Eilu 2006), in degraded land, urbanized land, coastline, savanna, and grassland of southern Africa (Nel et al. 2004; Rambuda and Johnson 2004; Terzano et al. 2018) and in several parts of Ethiopia (Fessehaie and Tessema 2014; Fufa et al. 2017; Shiferaw et al. 2018; Tamiru 2017). Its further expansion would worsen the problem, leading to great environmental and socio-economic damage.

Climate change has a profound effect on the introduction and establishment of invasive species (Roura-Pascual et al. 2011). Climate warming could facilitate the dispersal and performance of invasive alien species, which would allow range expansion and new invasions (Thiney et al. 2019; Walther et al. 2009). Moreover, climate change facilitates the distribution of alien species into new areas through removing constraints to species dispersal and survival such as temperature or moisture (Hellmann et al. 2008; Mainka and Howard 2010). It is also the main driving factor facilitating the establishment and spread of invasive alien species (Burgiel and Muir 2010).

Recent studies showed that climate change is one of the factors governing the invasion of invasive species in several parts of Africa (Sintayehu et al. 2020a; Sintayehu et al. 2020b). Similarly, climate change may create an opportunity for the establishment and invasion of S. didymobotrya. Thus, examining the relationship between the invasion of invasive species and climate change is crucial to design appropriate strategies, hence to mitigate their expansion and potential adverse impacts. Therefore, this study examined the current and future habitat suitability for S. didymobotrya invasion in the continent of Africa under the current and future climatic scenarios. This study addresses the long-term projected impact of climate change in the distribution and spatial extent of the species at the continent level (Africa). Moreover, as to our knowledge, this is the first-ever study that made use of species distribution modeling (ensemble model) to examine the current and future habitat suitability of S. didymobotrya invasion in Africa under changing climate conditions.

\section{Materials and methods Target species}

Senna didymobotrya is flowering plant species in the family Fabaceae. In several parts of Africa, the species is named "African senna," "candelabra tree," "popcorn senna," and "peanut butter cassia" (Jaca and Condy 2017). It is a hairy, aromatic shrub growing up to $9 \mathrm{~m}$. It has been domesticated for many areas as an ornamental plant, a cover crop, and leguminous green manure. The plant commonly grows in the tropical climate on diverse habitats and is native to eastern and central Africa (Orwa et al. 2009). The leaf extracts from S. didymobotrya are used as traditional medicine (Jaca and Condy 2017; Jeruto et al. 2017). The species is distributed from Congo east to Ethiopia and south to Namibia, Zimbabwe, Angola, Mozambique, Comoros, Madagascar, Mauritius, and South Africa (Orwa et al. 2009; Tabuti 2007). The species is capable of establishing itself under light frost up to 25 days in a year (Dlamini 2016) but usually prefers a warmer climate. Its occurrence is favored by the presence of other species like Sesbania punicea, Melia azedarach, and Psidium guajava (Dlamini 2016). Moreover, the species often grows in ruderal areas with a steady water supply such as wetlands and riparian areas (Dlamini 2016; Tabuti 2007), water bodies, damp localities, grassland, and woodland (Nyaberi et al. 2013), with an altitude range from 900 up to $2500 \mathrm{~m}$ above sea level (Tabuti 2007). 


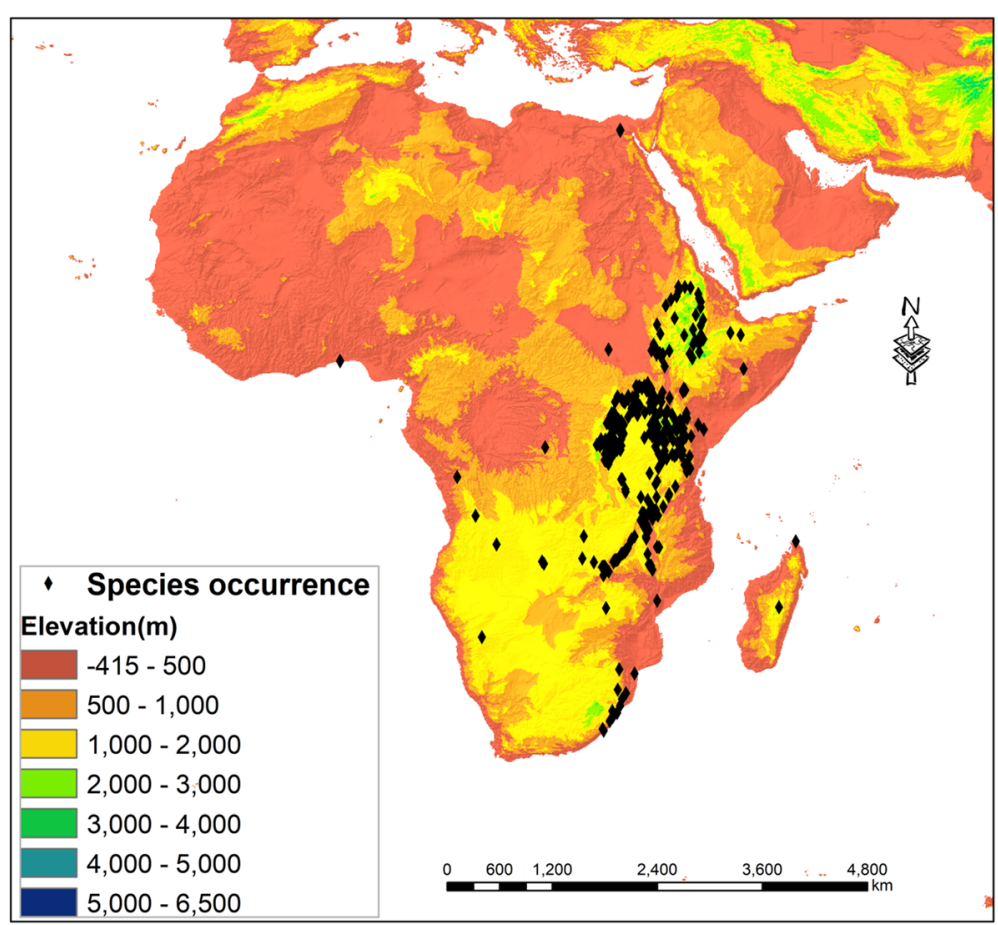

Fig. 1 Spatial distribution of species occurrence across elevation range

\section{Species presence records}

Species occurrence data were accessed from the Global Biodiversity Information Facility (GBIF: 105 https:// www.gbif.org/), Vegetationmap4africa (597: https://vegetationmap4africa.org/), and the South African National Biodiversity Institute (SNABI: 11, http://ipt.sanbi.org.za/ iptsanbi/) databases (Fig. 1). A visual inspection was done using the acquired georeferenced points in ESRI ArcMap 10.7 software. The data were checked, and duplicate records were removed from the dataset. Finally, a total of 515 presence points were used as input for species distribution modeling (SDM). Furthermore, to reduce the influence of false absence during modeling, we generated 800 randomly distributed pseudo-absence points over the geographical surface.

\section{Environmental and climate data}

For the prediction of the current and future distribution of $S$. didymobotrya, 19 bioclimatic and one elevation variables were acquired from WorldClim (www.worldclim. com) database version 2.1. The data has a resolution of 5 arc minutes which is approximately $10 \mathrm{~km}$ at the equator. The dataset was interpolated from the measurement taken in more than 10,000 weather stations across the world (Hijmans et al. 2005). The data was downloaded in GeoTiff (.tif) format using the getData raster package (Naimi 2018: https://cran.r-project.org) in R. Since the collinearity problem might result in model instability and wrong interpretation (Dormann et al. 2013), all the acquired bioclimatic data were undergone for the collinearity test. Variance inflation factors (VIF) was used to assess the collinearity among variables using the SDM package in R (Marquardt 1970). Pearson's correlation coefficients were used to find out the correlation between environmental variables, and variables with the highest correlation coefficient $(r>0.7)$ were excluded from the model (Dormann et al. 2013) to avoid the effect of multi-collinearity. Finally, eight bioclimatic variables (consisting of four temperatures and four precipitations) and one topographic variable were maintained for modeling (Table 3).

Global climate models (GCMs) for two representative concentration paths such as RCP4.5 and RCP8.5 of the periods 2050 (2041-2060) and 2070 (2061-2080) were obtained from WorldClim open sources database (https://worldclim.org/data/v1.4/cmip5.html) representing the future climate projections (Fick and Hijmans 2017). According to van Vuuren et al. (2011), representative concentration pathway (RCP) scenarios are developed to illustrate climate situations in which radioactive forcing can be anticipated to rise by 4.5 and 8.5 in watts per square meter $\left(\mathrm{W} / \mathrm{m}^{-2}\right)$ in the year 2100 and are commonly used for historical climate change modeling (IPCC 2014).

\section{Species distribution modeling}

Species distribution models (SDMs) are a powerful tool used in many disciplines such as regional conservation 
planning, climate change impact assessment, and produce invasion risk mapping, ecology (Naimi 2015) and phylogeography (Alvarado-Serrano and Knowles 2014). They have a robust capability for predicting species probability of occurrence in geographical areas using the presence and absence data (Srivastava et al. 2019). SDMs can be run in the SDM package in R statistical software and through the ensemble approach which combines several statistical and machine learning algorithms (Marmion et al. 2009; Naimi and Araújo 2016). In our study, we employed a total of eight SDMs using three regression models: generalized linear model (GLM), generalized additive model (GAM), and multivariate adaptive regression splines (MARS). Besides, two classification models, i.e., flexible discriminant analysis (FDA) and mixed discriminant analysis (MAD), were applied. Three machine learning models such as random forest (RF), boosted regression trees (BRT), and support vector machine (SVM) were also used. The selected model types are among the most powerful models in handling the presence and absence of data; hence, predicting the species habitat suitability by generating a binary map is easier (Naimi and Ara 2016).

In this study, an ensemble modeling approach that combines the eight modeling results was used for predicting the current and future suitability map of the invasion by $S$. didymobotrya. The ensemble modeling was suggested as among the robust approaches in distribution modeling (Araújo and New 2007; Gómez et al. 2018; Hao et al. 2020; Marmion et al. 2009). The ensemble modeling approach has the potential to minimize the expected modeling result variability which may occur when using a single algorithm (Alfaro et al. 2018; Buisson et al. 2010; Turner et al. 2019). An ensemble model has been reported as the most efficient model in predicting different alien invasive species by Stohlgren et al. (2010) and Ng et al. (2018). A proper selection of parameters is critical in the ensemble approach and is still required to reduce the possible model uncertainties.

\section{Model performance: the current and future suitability area analysis}

The model predicting performance for the future and current area suitability for $S$. didymobotrya was evaluated based on the area under the curve (AUC) of receiver operating characteristics (ROC) (Fielding and Bell 1997) and true skill statistics (TSS) (Allouche et al. 2006) measure of the metric. The AUC values range from 0 to 1 whereas the TSS measuring metric values are between -1 and 1 (Naimi 2015). The different model AUC and TSS classification indexes are shown in Table 1 (Thuiller et al. 2009). The classification index illustrates the model prediction efficacy from low/fail to excellent ranges. We calibrated the models using the
Table 1 Index for classifying model prediction accuracy

\begin{tabular}{lll}
\hline Accuracy & AUC & TSS \\
\hline Excellent/high & $0.9-1$ & $0.8-1$ \\
Good & $0.8-0.9$ & $0.6-0.8$ \\
Fair & $0.7-0.8$ & $0.4-0.6$ \\
Poor & $0.6-0.7$ & $0.2-0.4$ \\
Fail/null & $0.5-0.6$ & $0-0.2$ \\
\hline
\end{tabular}

Source: Thuiller et al. (2009)

default setting which shares the data about $70 \%$ for training the model, and the remaining $30 \%$ of the data were used for assessing the performance of the model (Araújo et al. 2005).

In this study, the habitat suitability change analysis was performed based on future scenarios (2050 and 2070) under the two RCPs (4.5 and 8.5). The final map generated from the ensemble model was classified into four different suitability classes: (1) not suitable (0.0$0.25)$, (2) lowly suitable $(0.25-0.50)$, (3) moderately suitable (0.50-0.75), and (4) highly suitable (0.75-1.00), following the method of Hamid et al. (2019).

\section{Habitat vulnerability assessment}

This study followed the methods developed by Dai et al. (2019), Duan et al. (2016), and Li et al. (2018) to assess the potential habitat change under the future climate change scenarios. The suitability of habitats was computed based on the formula below:

$$
A C=\frac{(A f-A c)}{A c} \times 100
$$

where $A_{\mathrm{f}}$ is the area predicted as suitable habitat under 2050 and 2070 climatic conditions and $A_{\mathrm{c}}$ is the currently suitable habitat area predicted.

The key criteria used to evaluate habitat vulnerability were unsuitable habitats, new suitable habitats, suitable habitats that have not changed, and vulnerable areas. Unsuitable habitats are areas which presently and in the future (2050 and 2070) would remain unsuitable. New suitable habitats, on the other hand, are areas that are not currently invaded by $S$. didymobotrya but are predicted to be suitable by the 2050 and 2070 . The third criterion, suitable habitats that have not changed, refers to those places that are currently suitable habitats and would remain so in the future (2050 and 2070) whereas vulnerable areas are currently suitable habitats which are projected to become unsuitable by the year 2050 and 2070 .

\section{Results}

\section{Model performance statistics}

The overall model's percentage values of AUC and TSS were $95 \%$ and $81 \%$, respectively, and are higher than the 
Table 2 Mean model performance statistics of the eight models using test dataset for predicting the current and future area suitability of $\mathbf{S}$. didymobotrya tree species under different climatic scenarios

\begin{tabular}{|c|c|c|c|c|c|c|c|c|c|}
\hline \multirow{2}{*}{$\begin{array}{l}\text { Measure } \\
\text { of } \\
\text { statistics }\end{array}$} & \multicolumn{8}{|c|}{ Models } & \multirow[b]{2}{*}{ Mean value } \\
\hline & GLM & SVM & $\mathrm{RF}$ & BRT & MARS & GAM & MDA & FDA & \\
\hline AUC & 0.92 & 0.96 & 0.99 & 0.95 & 0.95 & 0.95 & 0.94 & 0.92 & 0.95 \\
\hline TSS & 0.76 & 0.83 & 0.92 & 0.81 & 0.80 & 0.83 & 0.78 & 0.77 & 0.81 \\
\hline Deviance & 0.68 & 0.52 & 0.30 & 0.76 & 0.59 & 0.82 & 0.67 & 0.71 & 0.63 \\
\hline Cor & 0.76 & 0.84 & 0.91 & 0.81 & 0.81 & 0.83 & 0.79 & 0.77 & 0.82 \\
\hline
\end{tabular}

expected random value of the model (Table 2). According to the model evaluation results, the performance of the ensemble model was very good for predicting the invasion of $S$. didymobotrya in Africa. The highest model AUC value was attained from RF algorithms (AUC = 99\%), while the lowest performance was obtained from the FDA and GLM algorithm (AUC $=92 \%$ ). The minimum and the maximum TSS values from the eight algorithms were $76 \%$ and $92 \%$ respectively. The lowest was recorded from GLM, and the highest was obtained from RF algorithms (Table 2).

\section{Environmental variables relative importance}

The relative contributions of each environmental variable for predicting the invasion of S. didymobotrya were shown in Table 3. The elevation accounted for 33\% of the relative contribution to determine the distribution of S. didymobotrya, followed by bio3 (27.3\%) and bio1 (20.6\%). The contribution of bio12 was $10.8 \%$. However, the mean temperature of the wettest quarter (boi8), the mean temperature of the driest quarter (bio9), and the precipitation of the warmest quarter (bio18) were the least governing factors that determine the distribution of the species with the overall contribution of $5.3 \%, 3.5 \%$, and $3.1 \%$, respectively.

\section{Current and future distribution of Senna didymobotrya} Model prediction showed that about $17.74 \%$ of Africa is climatically suitable for $S$. didymobotrya invasion under the current climatic conditions, of which $3.89 \%$, 3.76\%, and $10.09 \%$ are categorized as highly, moderately, and lowly suitable area respectively. However, the largest portion of the continent $(82.25 \%)$ is not suitable for $S$. didymobotrya (Table 4). The highly suitable areas are generally observed in Rwanda, Uganda, Western Kenya, Burundi, Tanzania, and most of Ethiopia, whereas Zambia, north-eastern Zimbabwe, Mozambique, the central part of Angola, Lesotho, Central Madagascar, eastern broader of South Africa, Malawi, the eastern part of Democratic Republic of Congo (DRC), South Sudan, and Eritrea are from lowly to moderately conducive for the invasion of $S$. didymobotrya (Fig. 2). Furthermore, the species suitable habitat range is observed in the elevation range between 750 to $3000 \mathrm{~m}$ a.s.l.; however, a few patches of suitability range are found at a lower elevation beyond $750 \mathrm{~m}$ a.s.l.

Future model projections revealed that the climatically suitable regions for S. didymobotrya invasion would increase in the 2050s and the 2070s (Fig. 3). The total share of habitats labeled as low and moderate class in the RCP 4.5 and RCP8.5 climatic scenarios for the year 2050 was projected to be $17.12 \%$ and $20.21 \%$ respectively. A similar trend was projected for the year 2070, with an increase in the suitability of $18.82 \%$ and $22.54 \%$ under RCP 4.5 and RCP 8.5 (Table 4 and Fig. 3) respectively. Our model prediction showed a reduction in the highly suitable area for $S$. didymobotrya invasion by $14.4 \%$ and $19.79 \%$ under RCP4.5 and RCP8.5

Table 3 The relative contribution (\%) of the environmental variables based on correlation metric

\begin{tabular}{lll}
\hline Environmental variables & Description & Percentage contribution \\
\hline elev & Elevation & 33 \\
bio6 & Min temperature of coldest month & 27.3 \\
boi1 & Annual mean temperature & 20.6 \\
boi12 & Annual precipitation & 10.8 \\
bio14 & Precipitation of driest month & 8.2 \\
boi17 & Precipitation of driest quarter & 7.8 \\
boi8 & Mean temperature of wettest quarter & 5.3 \\
bio9 & Mean temperature of driest quarter & 3.5 \\
bio18 & Precipitation of warmest quarter & 3.1 \\
\hline
\end{tabular}


Table 4 Percentage of total suitability and suitable habitat change with respect to the current distribution

\begin{tabular}{|c|c|c|c|c|c|c|c|c|c|}
\hline \multirow[b]{2}{*}{ Years } & \multicolumn{4}{|c|}{ Total suitability (\%) in different ranges } & \multirow[b]{2}{*}{ High } & \multicolumn{4}{|c|}{ Suitable habitat change rate (\%) } \\
\hline & Scenarios & Not suitable & Low & Moderate & & Not suitable & Low & Moderate & High \\
\hline Current & - & 82.25 & 10.09 & 3.76 & 3.89 & & & & \\
\hline \multirow[t]{2}{*}{2050} & RCP4.5 & 79.55 & 13.01 & 4.11 & 3.33 & -3.28 & 28.94 & 9.31 & -14.40 \\
\hline & RCP8.5 & 76.67 & 15.65 & 4.56 & 3.12 & -6.78 & 55.10 & 21.28 & -19.79 \\
\hline \multirow[t]{2}{*}{2070} & RCP4.5 & 78.05 & 14.52 & 4.3 & 3.13 & -5.11 & 43.90 & 14.36 & -19.54 \\
\hline & RCP8.5 & 74.76 & 17.65 & 4.89 & 2.7 & -9.11 & 74.93 & 30.05 & -30.59 \\
\hline
\end{tabular}

respectively by the year 2050 (Table 4). Similarly, in the year 2070, the highly suitable area will decrease by $19.54 \%$ and $30.59 \%$ under RCP4.5 and RCP 8.5 climate scenarios, respectively (Table 4).

Under RCP4.5 and RCP8.5 for the two considered period (2050 and 2070), Angola (southeastern), Zambia, Zimbabwe, DRC (northeast and central, partly to west), south African countries including Lesotho and Swaziland, Congo Brazzaville, western Namibia, southern Cotdivore, southern Ghana, and Cameron are among the hotspot areas for S. didymobotrya potential future invasion (Fig. 3 ). On the other hand, Mozambique and Ethiopia (northeastern) show a progressive loss in the current suitability of $S$. didymobotrya invasion. Likewise, a progressive decrease in the total suitability is observed for the eastern African countries which were previously considered the main hotspot area for S. didymobotrya (Fig. 3 and Table 4). However, in RCP8.5 (2050 and 2070), the percentage of areas invaded by the species is predicted to increase at a higher rate than that of RCP4.5. This surge is directed toward southern and slightly into central Africa. Nevertheless, under both future climatic scenarios, the continent, except Sub-Saharan countries, is not suitable for S. didymobotrya invasion.

Our model predicted a significant increase in the vulnerability of habitat for the invasion of S. didymobotrya under future climatic scenarios. The results demonstrated that by the 2050s, an increased rate in the new invasion areas by $61.57 \%$ and $79.82 \%$ was projected under RCP 4.5 and RCP 8.5 respectively (Table 5 and Fig. 3). Likewise, by the end of the century (the 2070s), this situation showed a progressive increase in suitability for the species by $73.12 \%$ and 95.62\% under RCP4.5 and RCP8.5 respectively. However, our assessment suggests a decrease in invasion for the high suitability classes.

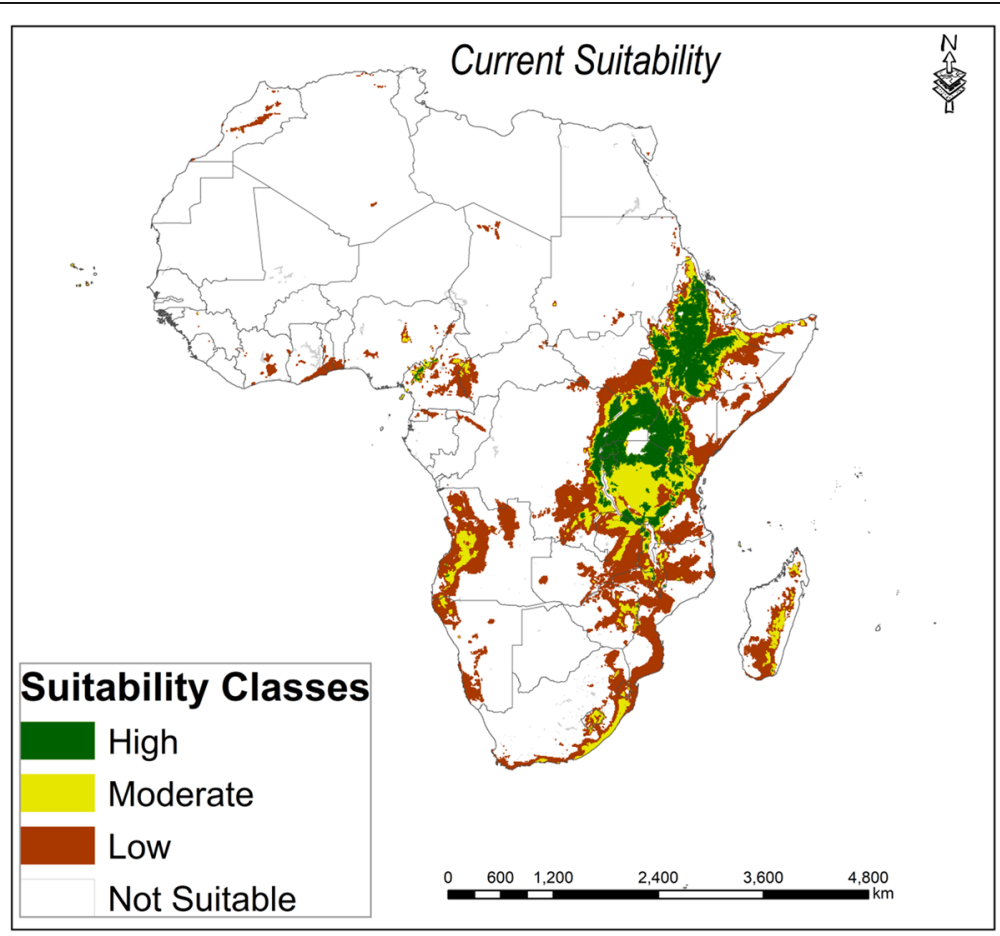

Fig. 2 S. didymobotrya invasions under current climatic conditions 

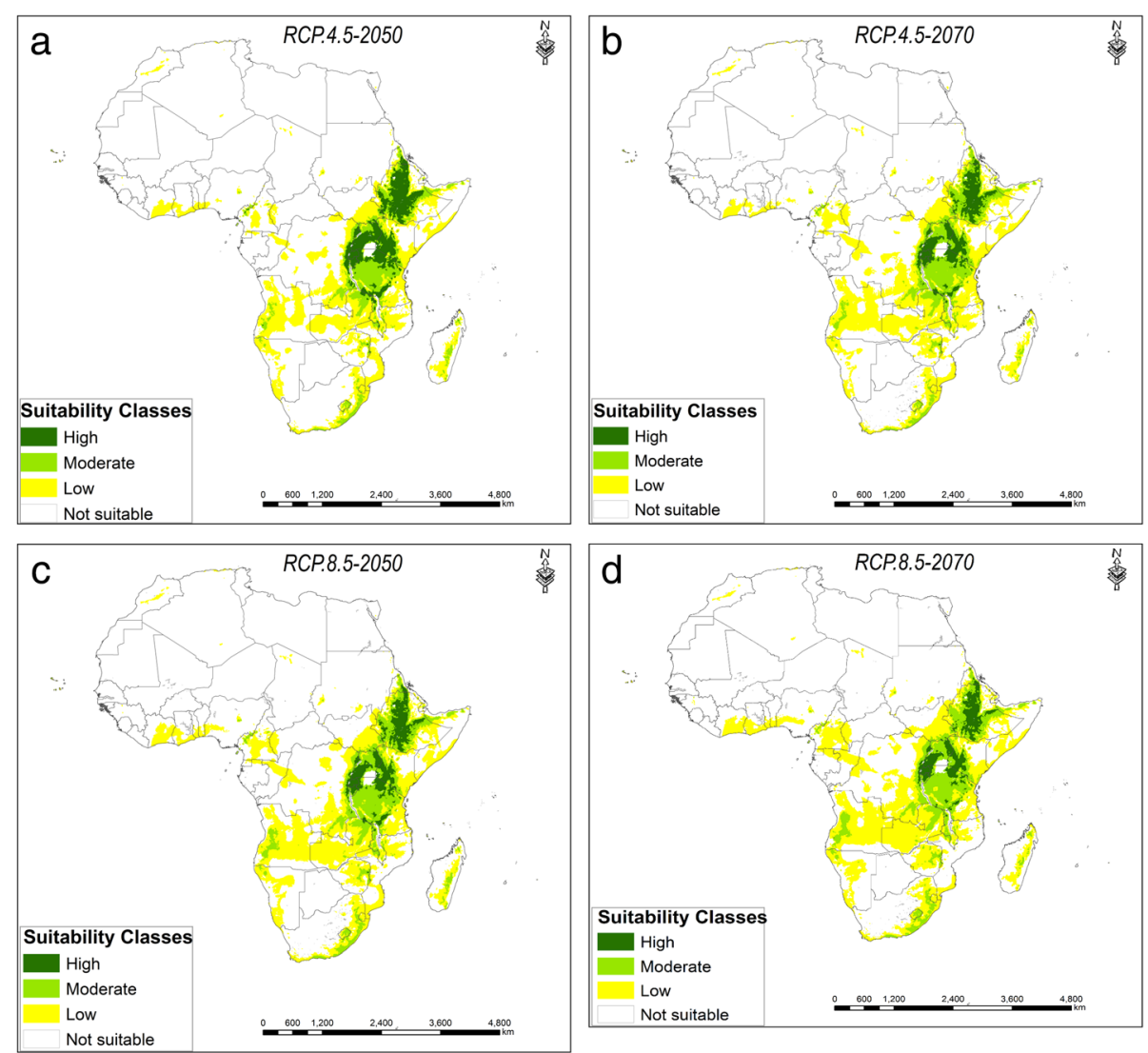

Fig. 3 S. didymobotrya invasion suitability under future projected climatic condition for RCP 4.5 and RCP 8.5

\section{Discussion}

This study estimated the current potential and future predicted habitat for S. didymobotrya in Africa using Ensemble Approach. We applied both AUC and TSS values to evaluate the model performance, and the model predicted the distribution of the species very well. The ensemble model for the first time showed the potential impact of current and future climate on the distribution of S. didymobotrya in Africa. Under the current climatic scenarios, high habitat suitability for the invasion is observed in countries like Rwanda, Burundi, Uganda, Kenya, Tanzania, and Ethiopia. On the contrary, northern African countries were projected to be the nonsuitable habitat for $S$. didymobotrya invasion under current and future climatic conditions. Our present

Table 5 The percentage of future suitable habitat increase rate

\begin{tabular}{llllll}
\hline \multicolumn{5}{l}{ Future suitable habitat increase rate in (\%) by $\mathbf{2 0 5 0}$ and $\mathbf{2 0 7 0}$} \\
\hline Years & Scenarios & Not suitable & Low & Moderate & High \\
\hline 2050 & RCP4.5 & -1.94 & 36.48 & 25.09 & -2.71 \\
& RCP8.5 & -1.71 & 47.05 & 32.78 & -3.05 \\
2070 & RCP4.5 & -1.79 & 42.42 & 30.70 & -3.41 \\
& RCP8.5 & -2.23 & 55.23 & 40.39 & -3.01 \\
\hline
\end{tabular}

result concurs with that of the report made by Witt and Luke (2017), which put Senna spp. as among the most occurring alien invasive species in many habitats of eastern and southern African countries. Furthermore, our current invasion distribution model result is in parallel with studies conducted in different parts of Africa (Dlamini 2016; Fessehaie and Tessema 2014; Fufa et al. 2017; Jaca and Condy 2017; Nel et al. 2004). Like the study by Bellard et al. (2018) proves that climate change has affected the distribution of invasive species causing expansions in climatically suitable habitats worldwide, this research evinces that future climate change would cause a similar increase of invasion in the climatically suitable areas of S. didymobotrya in Africa. The predicted maps provided by this study will be helpful for the prevention and early detection of the species in the new areas.

Under future climate change scenarios, suitability for $S$. didymobotrya will expand toward lower elevations. Higher species richness of invasive alien species was reported in the lower elevation ranges than higher elevation (Averett et al. 2016; Ibanez et al. 2019; Pauchard and Alaback 2004). Similarly, some invasive species are shifting their geographic distribution toward high altitude as the climate warms (Bradley et al. 2010; Shrestha 
et al. 2018), and new invasive species are adding to those currently being successfully controlled. This could be because higher elevation ranges are assumed to be isolated and distant from weed populations subsequently hindering accessibility by vehicular traffic and less human disturbance that leads to less propagule pressure across the landscape resulting in a low establishment. This means that in the long run, the inherent characteristic of the species and lack of native competitors may cause a niche shift in new ranges toward lower elevations, and it is more possible that climate variability will facilitate the spread of the species into new areas.

Following topographic information, temperature variables (accounting for 47.9\%) (bio6, min temperature of coldest month, and bio1, annual mean temperature) were among variables predicted to be important for S. didymobotrya establishment. Similarly, our ensemble model predicted precipitation variables which are accounting for 26.8\% (bio12, annual precipitation; bio14, precipitation of driest month; and bio17, precipitation of driest quarter) as the third most important environmental variables affecting S. didymobotrya distribution. Ibanez et al.(2019) also reported positive effects of mean annual precipitation on alien species coverage. Similarly, Averett et al. (2016) confirmed that temperature variables (minimum temperature records over 30 years) are the most predictor variables limiting the distribution of non-native species richness.

Our future projection model shows a substantial increase in the new invasion areas both for the considered RCPs 4.5 and 8.5 (Supplementary information, Table S1, Figure S1). Nevertheless, it is visualized that areas which are highly suitable under current climatic condition tend to lose their suitability into moderate and low suitability ranges under the future climatic condition. The model predicted, compared to the current suitability, the southern African countries are expected to gain more new invaded areas than those of the countries located in the eastern Africa and central Africa in the future climatic scenarios (Supplementary information, Figure S1). This trend indicates a shift in the future hotspot area invasion by $S$. didymobotrya into these countries as a result of climate change. Nevertheless, despite the loss in a higher range of suitability, eastern African countries remain the main hotspot location of $S$. didymobotrya future invasion. According to Witt and Luke (2017) and Witt et al. (2018), the future alien invasive plant species distribution including S. didymobotrya in most habitat range of eastern African countries is highly facilitated by increased land degradation, overgrazing, deforestation of native forest, and the associated impacts of climate change.

Climate change can cause alien species to migrate into new place from the currently growing habitats (Walther et al. 2009). By the same token, in our study, we found a significant shift in the future range of niche of $S$. didymobotrya invasion from the current growing range, which is articulated as the effect of climate change. Moreover, this study predicts that, in the long run due to the ongoing climate changes, there would be potential shift in species' habitat ranges. What is more, the movement of invasive species into the new areas at the global and local scale is favored by other mechanisms such as wind (cyclone), severe weather events, global circulation air, and water and climate changes (Burgiel and Muir 2010).

\section{Conclusion}

This study confirms for the first time the distribution of $S$. didymobotrya. Both the present and future projections show the presence of $S$. didymobotrya in most of the African countries. We found that eastern African countries are more vulnerable to $S$. didymobotrya invasion in the future, followed by southern African countries. The current status and future trend of $S$. didymobotrya indicate a precautionary note calling for coordinated, inter-country, and large-scale interventions. Additionally, the outputs of this study will support the management of the species through early detection of future potentially suitable areas. Based on our study, we urge that the future conservation strategy and policy direction should target how to limit the increasing expansion of invasion mainly by focusing on the hotspot areas through designing more feasible management and control measures through early identification and eradication actions. There is a need for more studies to provide more information on the distribution of $S$. didymobotrya at the local scale, by incorporating other variables such as land cover/use, population, proximity to water and roads, and population parameters.

\section{Supplementary Information}

The online version contains supplementary material available at https://doi. org/10.1186/s13717-020-00277-y.

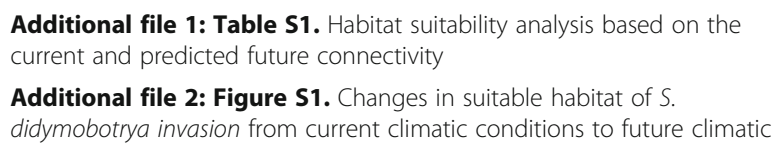

Additional file 2: Figure S1. Changes in suitable habitat of $S$.

didymobotrya invasion from current climatic conditions to future climatic conditions (year 2050 and 2070) for RCP 4.5 and RCP 8.5.

\section{Abbreviations \\ IPCC: Intergovernmental Panel on Climate Change; RCPs: Representative Concentration Pathways; GCM: Global climate models; SDM: Species distribution model}

\section{Acknowledgements}

The authors would like to thank Professor John Tabuti (Makerere University) and Mr. Yeneneh Wubetu (Haramaya University, Department of English) for editing the English language, grammar, and the content of the manuscript.

\section{Authors' contributions}

EChW designed the study, analyzed the data, reviewed the literature, and wrote the manuscripts. SWD initiated the work, edited the manuscript, and read the final manuscript. The authors read and approved the final manuscript. 


\section{Funding}

This research was funded by the researcher's resources.

\section{Availability of data and materials}

Please contact the author for data requests, and the data will be available online upon your request

\section{Ethics approval and consent to participate}

Not applicable

\section{Consent for publication}

Not applicable

\section{Competing interests}

The authors declare that they have no competing interests.

\section{Author details}

'Department of Geo-information Science, Haramaya University, Dire Dawa, Ethiopia. ${ }^{2}$ College of Agriculture and Environmental Sciences, Haramaya University, Dire Dawa, Ethiopia.

Received: 31 July 2020 Accepted: 1 December 2020 Published online: 07 January 2021

\section{References}

Alfaro E, Gámez M, García N (2018) Ensemble Classification Methods with Applications in R. (E. Alfaro, M. Gámez, \& N. García, Eds.) (First Edit). Chichester: Wiley, Ltd. https://doi.org/10.1002/9781119421566

Allouche O, Tsoar A, Kadmon R (2006) Assessing the accuracy of species distribution models: prevalence, kappa and the true skill statistic (TSS). J Appl Ecol 43(6):1223-1232. https://doi.org/10.1111/j.1365-2664.2006.01214.x

Alvarado-Serrano DF, Knowles LL (2014) Ecological niche models in phylogeographic studies: applications, advances and precautions. Mol Ecol Resour 14(2):233-248. https://doi.org/10.1111/1755-0998.12184

Araújo MB, New M (2007) Ensemble forecasting of species distributions. Trends Ecol Evol 22(1):42-47. https://doi.org/10.1016/j.tree.2006.09.010

Araújo MB, Pearson RG, Thuiller W, Erhard M (2005) Validation of species-climate impact models under climate change. Glob Chang Biol 11:1504-1513. https://doi.org/10.1111/j.1365-2486.2005.01000.x

Averett JP, McCune B, Parks CG, Naylor BJ, DelCurto T, Mata-González R (2016) Non-native plant invasion along elevation and canopy closure gradients in a middle rocky mountain ecosystem. PLoS One 11(1):e0147826. https://doi.org/ 10.1371/journal.pone.0147826

Bellard C, Jeschke JM, Leroy B, Mace GM (2018) Insights from modeling studies on how climate change affects invasive alien species geography. Ecol Evol 8 : 5688-5700.https://doi.org/10.1002/ece3.4098

Bradley BA, Blumenthal DM, Wilcove DS, Ziska LH (2010) Predicting plant invasions in an era of global change. Trends Ecol Evol 25(5):310-318. https:// doi.org/10.1016/j.tree.2009.12.003

Buisson L, Thuiller W, Casajus N, Lek S, Grenouillet G (2010) Uncertainty in ensemble forecasting of species distribution. Glob Chang Biol 16(4):11451157. https://doi.org/10.1111/j.1365-2486.2009.02000.x

Burgiel SW, Muir AA (2010) Invasive species, climate change and ecosystembased adaptation: addressing multiple drivers of global change. Global Invasive Species Programme (GISP), Washington, DC and Nairobi. https://doi. org/10.13140/2.1.1460.8161

Dai Y, Hacker CE, Zhang Y, Li W, Zhang Y, Liu H et al (2019) Identifying climate refugia and its potential impact on Tibetan brown bear (Ursus arctos pruinosus) in Sanjiangyuan National Park, China. Ecol Evol 9(23):13278-13293. https://doi.org/10.1002/ece3.5780

Dlamini WMD (2016) Spatial analysis of invasive alien plant distribution patterns and processes using Bayesian network-based data mining. Retrieved from http://uir.unisa.ac.za/handle/10500/20692

Dormann CF, Elith J, Bacher S, Buchmann C, Carl G, Carré G et al (2013) Collinearity: a review of methods to deal with it and a simulation study evaluating their performance. Ecography 36(1):27-46. https://doi.org/10.1111/ j.1600-0587.2012.07348.x

Duan RY, Kong XQ, Huang MY, Varela S, Ji X (2016) The potential effects of climate change on amphibian distribution, range fragmentation and turnover in China. PeerJ 4:e2185. https://doi.org/10.7717/peerj.2185
Fessehaie R, Tessema T (2014) Alien plant species invasions in Ethiopia: challenges and responses. In: International workshop on Parthenium weed in Ethiopia, Addis Ababa, p 65

Fick SE, Hijmans RJ (2017) WorldClim 2: new 1-km spatial resolution climate surfaces for global land areas. Int J Climatol 37(12):4302-4315. https://doi. org/10.1002/joc.5086

Fielding AH, Bell JF (1997) A review of methods for the assessment of prediction errors in conservation presence/absence models. Environ Conserv 24(1):3849. https://doi.org/10.1017/S0376892900021214

Fufa A, Tessema T, Hundessa N (2017) Distribution and abundance of emerging invasive weeds in central. Western Part Ethiopia 12(13):1121-1127. https:// doi.org/10.5897/AJAR2016.11922

Gómez D, Salvador P, Sanz J, Casanova C, Taratiel D, Casanova JL (2018) Machine learning approach to locate desert locust breeding areas based on ESA CCI soil moisture. J Appl Remote Sens 12(3):036011. https://doi.org/10.1117/1.jrs. 12.036011

Hamid M, Khuroo AA, Charles B, Ahmad R, Singh CP, Aravind NA (2019) Impact of climate change on the distribution range and niche dynamics of Himalayan birch, a typical treeline species in Himalayas. Biodivers Conserv 28(8-9):2345-2370. https://doi.org/10.1007/s10531-018-1641-8

Hao T, Elith J, Lahoz-Monfort JJ, Guillera-Arroita G (2020) Testing whether ensemble modelling is advantageous for maximising predictive performance of species distribution models. Ecography 43(4):549-558. https://doi.org/10. 1111/ecog.04890

Hellmann JJ, Byers JE, Bierwagen BG, Dukes JS (2008) Five potential consequences of climate change for invasive species. Conserv Biol 22(3):534543. https://doi.org/10.1111/j.1523-1739.2008.00951.x

Hijmans RJ, Cameron SE, Parra JL, Jones PG, Jarvis A (2005) Very high resolution interpolated climate surfaces for global land areas. Int J Climatol 25(15):19651978. https://doi.org/10.1002/joc.1276

Ibanez T, Hart P, Ainsworth A, Gross J, Monello R (2019) Factors associated with alien plant richness, cover and composition differ in tropical island forests. Divers Distrib 25(12):1910-1923. https://doi.org/10.1111/ddi.12989

IPCC (2014) Climate change 2014: synthesis report. Contribution of Working Groups I, II and III to the Fifth Assessment Report of the Intergovernmental Panel on Climate Change [Core Writing Team, R.K. Pachauri and L.A. Meyer (eds.)], Geneva. https://doi.org/10.1016/S0022-0248(00)00575-3

Jaca TP, Condy G (2017) Senna didymobotrya. Flowering Plants Afr 65:68-75

Jeruto P, Arama PF, Anyango B, Maroa G (2017) Phytochemical screening and antibacterial investigations of crude methanol extracts of Senna didymobotrya (Fresen.) H. S. Irwin \& Barneby. J Appl Biosci 114(1):1135711367. https://doi.org/10.4314/jab.v114i1.9

Li J, Li D, Xue Y, Wu B, He X, Liu F (2018) Identifying potential refugia and corridors under climate change: a case study of endangered Sichuan golden monkey (Rhinopithecus roxellana) in Qinling Mountains, China. Am J Primatol 80(11):e22929. https://doi.org/10.1002/ajp.22929

Luizza MW, Wakie T, Evangelista PH, Jarnevich CS (2016) Integrating local pastoral knowledge, participatory mapping, and species distribution modeling for risk assessment of invasive rubber vine (Cryptostegia grandiflora) in Ethiopia's Afar region. Ecol Soc 21(1):22. http://dx.doi.org/10.5751/ES-07988-210122

Mainka SA, Howard GW (2010) Climate change and invasive species: double jeopardy. Integ Zool 5(2):102-111.https://doi.org/10.1111/j.1749-4877.2010. 00193.x

Marmion M, Parviainen M, Luoto M, Heikkinen RK, Thuiller W (2009) Evaluation of consensus methods in predictive species distribution modelling. Divers Distrib 15(1):59-69. https://doi.org/10.1111/j.1472-4642.2008.00491.x

Marquardt DW (1970) Generalized inverses, ridge regression, biased linear estimation, and nonlinear estimation. Technometrics 12(3):591-612

Masters G, Norgrove L (2010) Climate change and invasive alien species (No. 1)

Naimi B (2015) On uncertainty in species distribution modelling (PhD disser). University of Twente, ITC. https://doi.org/10.3990/1.9789036538404

Naimi B (2018) Species distribution modelling with $R$

Naimi B, Ara MB (2016) Sdm: a reproducible and extensible $R$ platform for species distribution modelling. Ecography 39(4):368-375. https://doi.org/10.1111/ ecog. 01881

Nel JL, Richardson DM, Rouget M, Mgidi TN, Mdzeke N, Le Maitre DC et al (2004) A proposed classification of invasive alien plant species in South Africa: towards prioritizing species and areas for management action. South Afr J Sci 100:53-64

Ng WT, Cândido de Oliveira Silva A, Rima P, Atzberger C, Immitzer M (2018) Ensemble approach for potential habitat mapping of invasive Prosopis spp. in Turkana, Kenya. Ecol Evol 8(23):11921-11931. https://doi.org/10.1002/ece3.4649 
Nyaberi M, Onyango C, Maina J, Makobe M (2013) Bioactive fractions in the stem charcoal of Senna didymobotrya Freasen Irwin and Barney used by pastoral communities in west Pokot to preserve milk. Nat Res Manage 16:980-985

Orwa C, Mutua A, Kindt R, Jamnadass R, Simons A (2009) Agroforestree database: a tree reference and selection guide version 4.0 | world agroforestry | transforming lives and landscapes with trees. Retrieved June 4, 2020, from http://www.worldagroforestry.org/publication/agroforestree-database-treereference-and-selection-guide-version-40

Pauchard A, Alaback PB (2004) Influence of elevation, land use, and landscape context on patterns of alien plant invasions along roadsides in protected areas of south-central Chile. Conserv Biol 18:238-248. https://doi.org/10.1111/ j.1523-1739.2004.00300.x

Rambuda TD, Johnson SD (2004) Breeding systems of invasive alien plants in South Africa: does Baker's rule apply? Divers Distrib 10:409-416

Richardson DM, Rejmanek M (2011) Trees and shrubs as invasive alien species - a global review. Divers Distrib 17:788-809. https://doi.org/10.1111/j.1472-4642. 2011.00782.x

Roura-Pascual N, Hui C, Ikeda T, Leday G, Richardson DM, Carpintero S et al (2011) Relative roles of climatic suitability and anthropogenic influence in determining the pattern of spread in a global invader. Proc Natl Acad Sci U S A 108(1):220-225. https://doi.org/10.1073/pnas.1011723108

Shiferaw W, Bekele T, Demissew S, Aynekulu E (2020) Socio-ecological impacts of invasive plant species in Ethiopia: a review. J Agric Forest Meteorol Res 3(2): 292-296

Shiferaw W, Demissew S, Bekele T (2018) Invasive alien plant species in Ethiopia: ecological impacts on biodiversity a review paper. Int J Mol Biol 3(4):171-178. https://doi.org/10.15406/ijmboa.2018.03.00072

Shrestha UB, Sharma KP, Devkota A, Siwakoti M, Shrestha BB (2018) Potential impact of climate change on the distribution of six invasive alien plants in Nepal. Ecol Indic 95:99-107. https://doi.org/10.1016/j.ecolind.2018.07.009

Simberloff D, Martin JL, Genovesi P, Maris V, Wardle DA, Aronson J et al (2013) Impacts of biological invasions: what's what and the way forward. Trends Ecol Evol 28(1):58-66. https://doi.org/10.1016/j.tree.2012.07.013

Sintayehu DW, Dalle G, Bobasa AF (2020) Heliyon Impacts of climate change on current and future invasion of Prosopis juliflora in Ethiopia: environmental and socio-economic implications. Heliyon 6:e04596. https://doi.org/10.1016/j. heliyon.2020.e04596

Sintayehu DW, Egeru A, Ng WT, Cherenet E (2020) Regional dynamics in distribution of Prosopis juliflora under predicted climate change in Africa. Tropical Ecology 61(4):437-445. https://doi.org/10.1007/s42965-020-00101-w

Srivastava V, Lafond V, Griess VC (2019) Species distribution models (SDM): applications, benefits and challenges in invasive species management. In: CAB Reviews: Perspectives in Agriculture, Veterinary Science, Nutrition and Natural Resources. https://doi.org/10.1079/PAVSNNR201914020

Stohlgren TJ, Ma P, Kumar S, Rocca M, Morisette JT, Jarnevich CS, Benson N (2010) Ensemble habitat mapping of invasive plant species. Risk Anal 30(2): 224-235. https://doi.org/10.1111/j.1539-6924.2009.01343.x

Tabuti JRS (2007) Globinmed - Senna didymobotrya (Fresenius) Irwin \& Barneby. Retrieved June 5, 2020, from https://www.globinmed.com/index. php?option=com_content\&view=article\&id=79462:senna-didymobotryafresenius-irwin-a-barneby \&catid=8\&ltemid $=183$

Tamiru G (2017) Invasive alien weed species distribution, impacts on agriculture, challenge and reaction in Ethiopia: a review. J Biol Agric Healthcare 7(7):136146

Terzano D, Kotzé I, Marais C, Cianciullo S, Farcomeni A, Caroli P et al (2018) Environmental and anthropogenic determinants of the spread of alien plant species: insights from South Africa's quaternary catchments. Plant Ecol 219(3): 277-297. https://doi.org/10.1007/s11258-018-0795-5

Thiney U, Banterng P, Gonkhamdee S, Katawatin R (2019) Distributions of alien invasive weeds under climate change scenarios in mountainous Bhutan. Agronomy 9(8):442. https://doi.org/10.3390/agronomy9080442

Thuiller W, Lafourcade B, Araujo M (2009) "ModOperating manual for BIOMOD" in BIOMOD: species/climate modelling functions, R package version: 1-1 (2009). Université Joseph Fourier, Grenoble

Turner JA, Babcock RC, Kendrick GA, Hovey RK (2019) How does spatial resolution affect model performance? A case for ensemble approaches for marine benthic mesophotic communities. J Biogeogr 46(6):1249-1259. https://doi. org/10.1111/jbi.13581

van Vuuren DP, Edmonds J, Kainuma M, Riahi K, Thomson A, Hibbard K et al (2011) The representative concentration pathways: an overview. Clim Change 109(1):5-31. https://doi.org/10.1007/s10584-011-0148-z
Walther G, Roques A, Hulme PE, Sykes MT, Pys P, Robinet C, Semenchenko V (2009) Alien species in a warmer world: risks and opportunities. Trends Ecol Evol 24(12):686-693. https://doi.org/10.1016/j.tree.2009.06.008

Wilson JRU, Dormontt EE, Prentis PJ, Lowe AJ, Richardson DM (2009) Something in the way you move: dispersal pathways affect invasion success. Trends Ecol Evol 24:136-144. https://doi.org/10.1016/j.tree.2008.10.007

Winterbottom B, Eilu G (2006) Uganda Biodiversity and Tropical Forest Assessment Report. Whashington, DC, International Resources Group

Witt A, Beale T, van Wilgen BW (2018) An assessment of the distribution and potential ecological impacts of invasive alien plant species in eastern Africa. T Roy Soc S Afr 73:217-236. https://doi.org/10.1080/0035919X.2018.1529003

Witt A, Luke Q (2017) Guide to the naturalized and invasive plants of eastern Africa. CAB International, Wallingford, Oxon, UK. https://doi.org/10.1079/ 9781786392152.0000

Wittenberg R, Cock MJW (2001) Invasive alien species: a toolkit of best prevention and management practices. CAB International, Wallingford, Oxon, UK. https://doi.org/10.1079/9780851995694.0000

\section{Publisher's Note}

Springer Nature remains neutral with regard to jurisdictional claims in published maps and institutional affiliations.

\section{Submit your manuscript to a SpringerOpen ${ }^{\circ}$ journal and benefit from:}

- Convenient online submission

- Rigorous peer review

- Open access: articles freely available online

High visibility within the field

- Retaining the copyright to your article

Submit your next manuscript at $\boldsymbol{\nabla}$ springeropen.com 